\title{
A modular phosphate tether-mediated divergent strategy to complex polyols
}

\author{
Paul R. Hanson ${ }^{*}$, Susanthi Jayasinghe ${ }^{\ddagger}$, Soma Maitra ${ }^{\ddagger}$, Cornelius N. Ndi \\ and Rambabu Chegondi
}

\author{
Full Research Paper \\ Open Access \\ Address: \\ Department of Chemistry, University of Kansas, 1251 Wescoe Hall \\ Drive, Lawrence, KS 66045-7582, USA \\ Email: \\ Paul R. Hanson* - phanson@ku.edu \\ * Corresponding author $\ddagger$ Equal contributors \\ Keywords: \\ phosphate-tether; one-pot; sequential processes; organophosphorus; \\ polyol; stereodivergent \\ Beilstein J. Org. Chem. 2014, 10, 2332-2337. \\ doi:10.3762/bjoc. 10.242 \\ Received: 12 June 2014 \\ Accepted: 05 September 2014 \\ Published: 07 October 2014 \\ This article is part of the Thematic Series "Organophosphorus chemistry". \\ Associate Editor: S. You \\ (c) 2014 Hanson et al; licensee Beilstein-Institut. \\ License and terms: see end of document.
}

\begin{abstract}
An efficient and divergent synthesis of polyol subunits utilizing a phosphate tether-mediated, one-pot, sequential RCM/CM/reduction process is reported. A modular, 3-component coupling strategy has been developed, in which, simple "order of addition" of a pair of olefinic-alcohol components to a pseudo- $C_{2}$-symmetric phosphoryl chloride, coupled with the RCM/CM/reduction protocol, yields five polyol fragments. Each of the product polyols bears a central 1,3-anti-diol subunit with differential olefinic geometries at the periphery.
\end{abstract}

\section{Introduction}

1,3-anti-Diol subunits are a central component in several potent biologically active polyketides [1-4]. This prevalence has led to the development of various synthetic methods for their construction [5]. In particular, divergent strategies are ideal for analog generation [6-11], which in turn, can enhance the quality of screening decks in early phase drug discovery. One aim of divergent synthetic strategies is to produce multiple scaffolds from a single set of starting materials [12]. In this regard, onepot, sequential processes [13-16] are well suited to address this challenge by forming multiple bonds and stereocenters, while invoking step- [17], atom- [18-21], green- [22,23], and pot economy [24-26]. We have previously reported phosphate tether-mediated strategies to streamline the synthesis of 1,3anti-diol containing natural products, including recent reports employing one-pot, sequential protocols [27-32]. Herein, we report a modular, divergent approach to construct advanced polyol intermediates 10-14 and 17-21 in one- or two-pot sequences utilizing the innate properties of a phosphate tether. Taken collectively, this modular, divergent 3-component coupling strategy generates five polyol fragments, bearing differential $Z$ - and $E$-olefins, from a pair of olefinic-alcohol components $\mathbf{A}$ and $\mathbf{B}$ and a pseudo- $C_{2}$-symmetric phosphoryl chloride $(S, S)$-1. Moreover, the method relies on simple "order of addition" of components for the phosphoryl coupling, ring- 
closing metathesis (RCM) and cross metathesis (CM) steps of the process as outlined in Scheme 1. This protocol further highlights the utility of phosphate tether mediated desymmetrization of $C_{2}$-symmetric 1,3-anti-diene-diol subunit to generate polyol scaffolds which would otherwise be difficult to produce via $(Z)$-and $(E)$-selective CM of 1,3-anti-diene-diol subunits with olefinic-alcohol components.

\section{Results and Discussion}

The titled divergent strategy was initiated during efforts to further explore the utility of phosphate tethers. Previous reports emphasized the utilization of phosphate tethers in chemo- and diastereoselective reactions including one-pot, sequential RCM/ $\mathrm{CM} / \mathrm{H}_{2}$ protocols and their applications in total synthesis of various natural products [27-32]. In addition, the scope of phosphate-tethered methods was further expanded via extensive RCM studies of different triene subunits utilizing stereochemically divergent olefin partners [33]. Recently, the potential of phosphate tethered facilitated processes were highlighted in the pot-economical and efficient total synthesis of the antifungal agent strictifolione, whereby two consecutive phosphate tethermediated, one-pot, sequential protocols were employed [34].

The requisite trienes 5-7 for this study were generated via our previously reported coupling of the pseudo- $C_{2}$-symmetric phosphoryl chloride $(S, S)-\mathbf{1}$ with the olefinic alcohol components 2-4 [27-32]. The alcohol substrates are carefully chosen to incorporate exo-allylic methyl groups since previous RCM studies [33] showed that the productive RCM for 8-membered ring formation was observed only for the $S, S$ - configured trienes in the presence of an exo-methyl group at the allylic position (Figure 1).

Initial attempts were focused on generating the first set of five polyols starting from trienes $\mathbf{5}$ and $\mathbf{6}$ in a two-pot operation

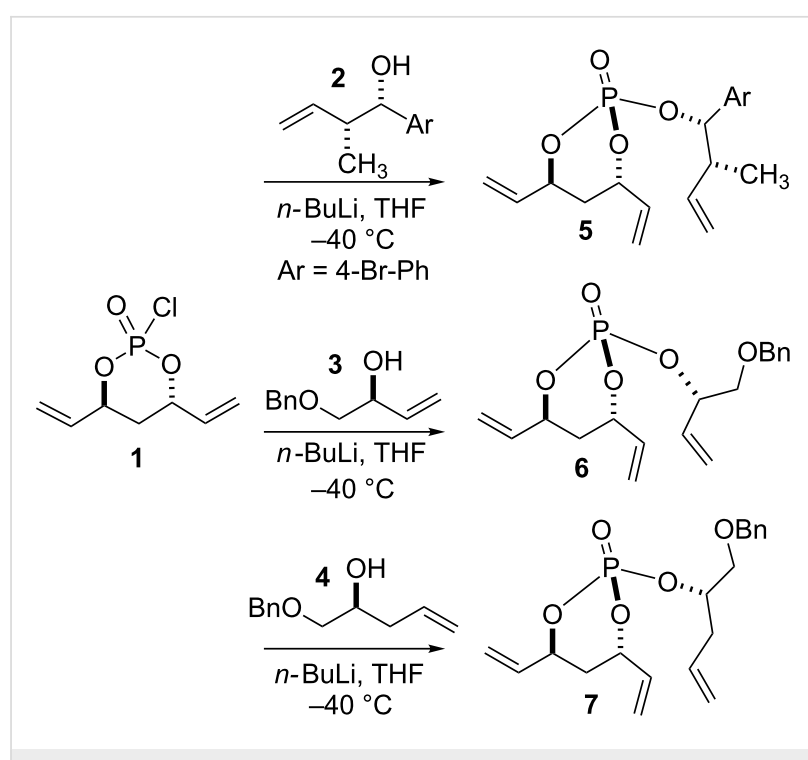

Figure 1: Synthesis of trienes 5-7.

(Scheme 2). The first operation entailed a one-pot, sequential $\mathrm{RCM} / \mathrm{CM} /$ chemoselective hydrogenation protocol [32], yielding two bicyclo[n.3.1]phosphate intermediates $\mathbf{8}$ and $\mathbf{9}$, and a second pot $\mathrm{LiAlH}_{4}$ reduction to provide the $Z$-configured tetraol subunits $\mathbf{1 0}$ and $\mathbf{1 1}$. Trienes $\mathbf{5}$ and $\mathbf{6}$ were generated via coupling with alcohol partners $\mathbf{2}$ and $\mathbf{3}$, respectively, and the divergent aspect of the method was introduced by simple switching of the olefinic partners in the subsequent $\mathrm{CM}$ reaction to afford five differentiated polyols starting from three coupling partners.

In this regard, triene 5 was first subjected to RCM in the presence of the Hoveyda-Grubbs II (HG-II) catalyst [35-37] in refluxing $\mathrm{CH}_{2} \mathrm{Cl}_{2}$, followed by solvent concentration and $\mathrm{CM}$ with allylic alcohol 3 in refluxing $\mathrm{CH}_{2} \mathrm{Cl}_{2}$ for two hours. It was observed that the use of $\mathrm{CH}_{2} \mathrm{Cl}_{2}$ was critical for the successful

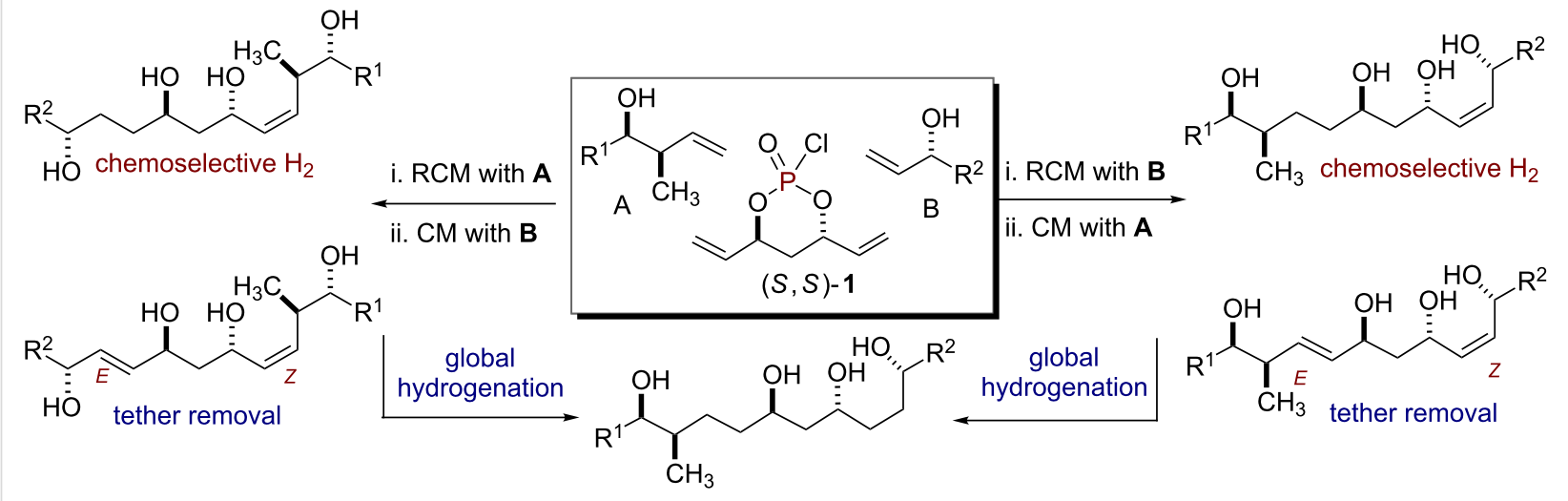




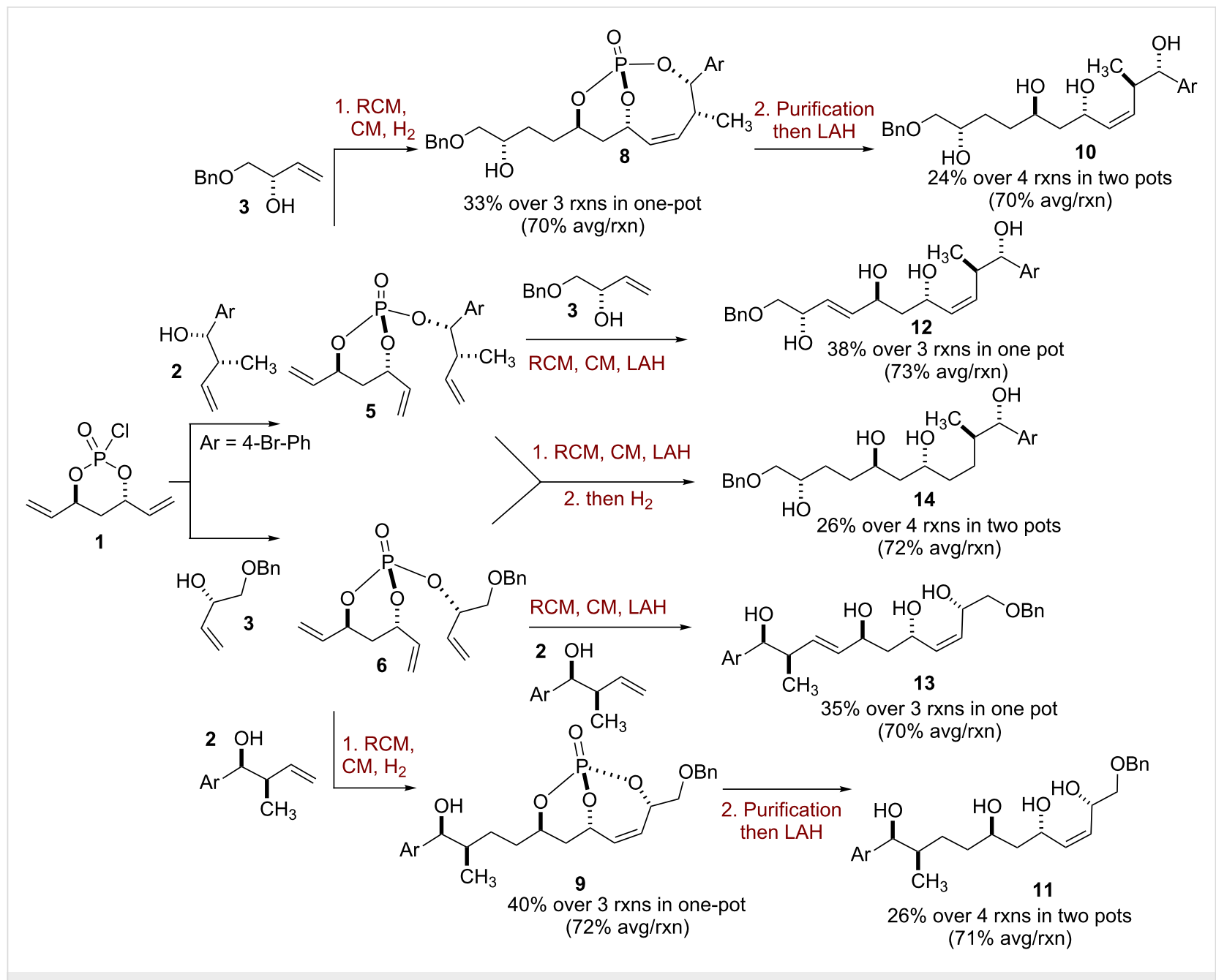

Scheme 2: Synthesis of polyols 10-14 in one-, two-pot sequential protocols.

$\mathrm{CM}$ reactions in order to avoid the formation of isomerized ketone byproducts. Subsequent chemoselective diimide reduction with $o$-nitrobenzenesulfonylhydrazine $(o-\mathrm{NBSH})[38-40]$ in $\mathrm{CH}_{2} \mathrm{Cl}_{2}$ at room temperature afforded bicyclo[5.3.1]phosphate 8 in 33\% overall yield, representing a $70 \%$ average yield/reaction in the one-pot, sequential protocol (Scheme 2). Subsequent treatment of $\mathbf{8}$ with $\mathrm{LiAlH}_{4}$ furnished the tetraol $\mathbf{1 0}$ in $24 \%$ overall yield over the course of four reaction steps carried out in two pots, representing a $70 \%$ average yield per reaction.

Similarly, starting with the triene 6 , a one-pot RCM/CM/ chemoselective $\mathrm{H}_{2}$ was performed to obtain the bicyclo[4.3.1]phosphate 9 in $40 \%$ yield over 3 reaction steps in a one-pot operation $(72 \% \mathrm{avg} / \mathrm{rxn})$. In this example, the RCM reaction was performed in dicholoroethane (DCE) at $70{ }^{\circ} \mathrm{C}$ for $2 \mathrm{~h}$, since lower reactivity was observed in $\mathrm{CH}_{2} \mathrm{Cl}_{2}$. Subsequently, phosphate 9 was treated with $\mathrm{LiAlH}_{4}$ to generate tetraol 11 in $26 \%$ overall yield in the four reactions carried out in two pots, representing a $71 \%$ average yield per reaction.
Next, a one-pot RCM/CM/LAH protocol was established to obtain two additional tetraol subunits possessing both $E$ - and $Z$-olefin geometries. Triene 5, was subjected to an RCM reaction, followed by a CM reaction with allylic alcohol 3. After removing the solvent, the CM product was treated with $\mathrm{LiAlH}_{4}$ to produce tetraol 12 in 38\% yield over three reaction steps in the one-pot, sequential process (73\% avg/rxn) (Scheme 2). Similarly, triene 6 was subjected to an RCM reaction, followed by $\mathrm{CM}$ with homoallylic alcohol $\mathbf{2}$, and subsequent treatment with $\mathrm{LiAlH}_{4}$ to afford tetraol $\mathbf{1 3}$ in 35\% yield over the three reaction steps, representing a $70 \% \mathrm{avg} / \mathrm{rxn}$ in the one-pot, sequential method.

This $\mathrm{RCM} / \mathrm{CM} / \mathrm{LAH}$ procedure was further merged with global hydrogenation, whereby the resulting tetraols $\mathbf{1 2}$ and 13, after one-pot, sequential RCM/CM/LAH protocol, were separately treated with $o$-NBSH to obtain tetraol 14 in $26 \%$ yield over the four reaction steps in a two-pot operation starting from triene $\mathbf{5}$ ( $72 \%$ avg/rxn). Utilizing this two-pot sequential protocol, the 
same tetraol 14 was obtained starting from two different trienes (5 and 6) and reacting with two different CM partners. It should be noted, that after phosphate tether removal, treatment of tetraol with $o$-NBSH (20 equiv), resulted in the global reduction of both $E$ - and $Z$-olefins in very good yields, while in contrast, diimide reduction in the presence of phosphate intermediates did not hydrogenate the endocyclic olefin even when large excesses of diimide reagent were employed (30 equiv) This empirical result further substantiates the protecting group ability of the phosphate tether for the endocyclic $Z$-olefin.

Next, our attempts were focused on generating the second set of five polyols starting from trienes $\mathbf{6}$ and 7. Utilizing the aforementioned strategy detailed in Scheme 2, triene 7 was subjected to the one-pot, sequential $\mathrm{RCM} / \mathrm{CM} /$ chemoselective $\mathrm{H}_{2}$ procedure and subsequent $\mathrm{LiAlH}_{4}$ reduction to generate tetraol 17 in $24 \%$ yield over 4 reaction steps in a two-pot operation $(70 \%$ avg/rxn) (Scheme 3). Further, starting with the same triene 6, which was previously used in Scheme 2, but utilizing a different cross-metathesis partner (homoallylic alcohol 4), a different tetraol $\mathbf{1 8}$ was generated in $23 \%$ yield over the four reaction steps in a two-pot operation (69\% avg/rxn) (Scheme 3).

In a similar manner, starting with triene $7, \mathrm{RCM}$ and subsequent $\mathrm{CM}$ with allylic alcohol $\mathbf{3}$, followed by tether removal with $\mathrm{LiAlH}_{4}$, were performed to obtain tetraol 19 in $42 \%$ yield over three reaction steps in the one-pot, sequential operation (75\% avg/rxn). Triene 6 was next subjected to RCM, followed by $\mathrm{CM}$ with homoallylic alcohol 4 and $\mathrm{LiAlH}_{4}$ reduction to furnish tetraol $\mathbf{2 0}$ in an overall $40 \%$ yield over three reaction steps in a one-pot operation ( $72 \%$ avg/rxn). Tetraols 19 and 20 were separately subjected to a global hydrogenation using $o$-NBSH to afford tetraol 21 in 34\% yield over four reaction steps in a two-pot operation starting from triene $\mathbf{6}$ $(77 \%$ avg/rxn).

\section{Conclusion}

In conclusion, we have reported one- or two-pot sequential methods mediated by a phosphate tether to generate a diverse array of polyol molecules utilizing readily prepared trienes 5, 6

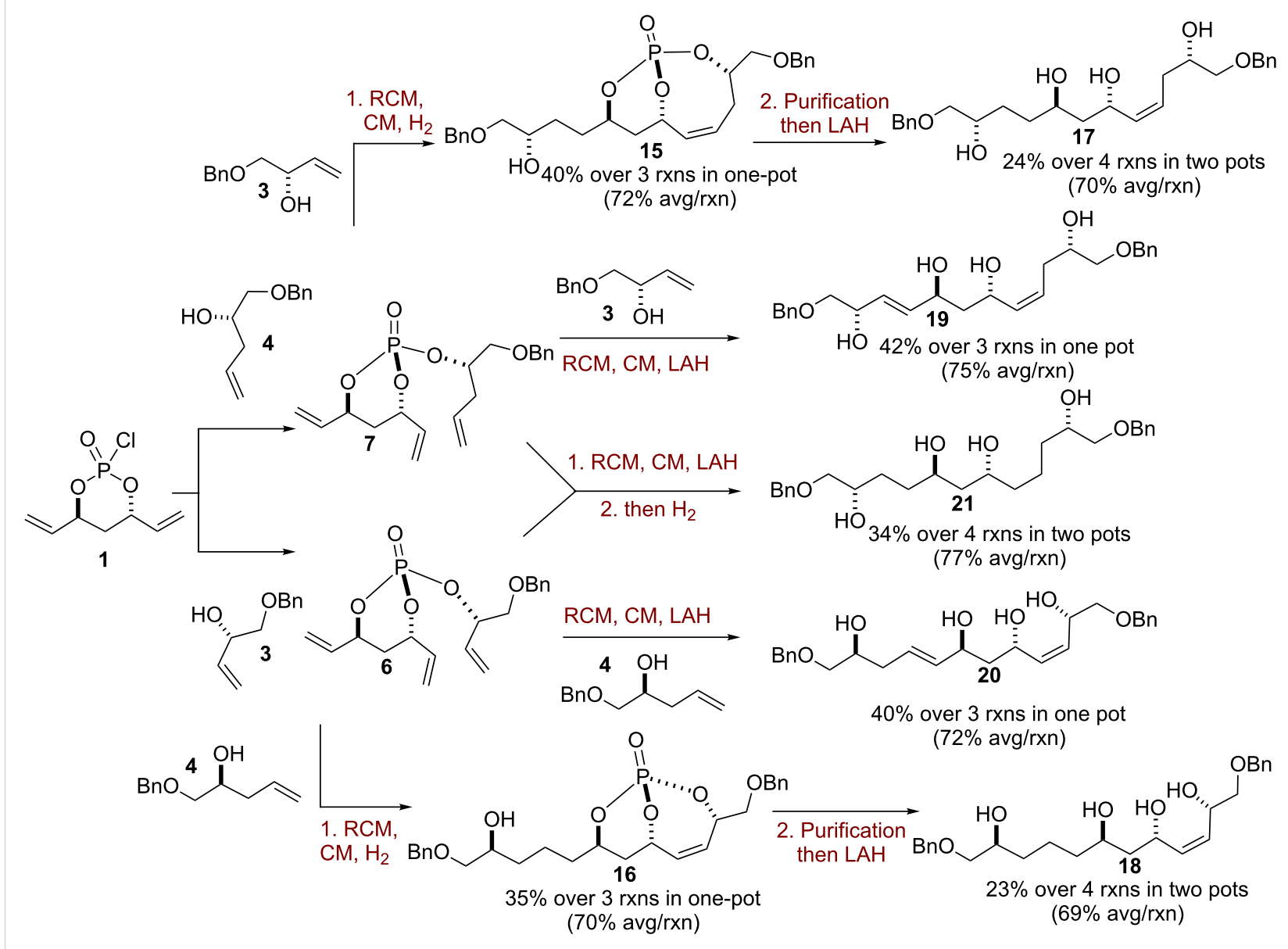


and $\mathbf{7}$ and CM partners $\mathbf{2 , 3}$, and $\mathbf{4}$. This divergent method was established by taking advantage of the innate properties of phosphate tethers to provide efficient syntheses of the stereochemically-rich polyol subunits 10-14 and 17-21.

\section{Supporting Information}

\section{Supporting Information File 1}

Experimental section.

[http://www.beilstein-journals.org/bjoc/content/

supplementary/1860-5397-10-242-S1.pdf]

\section{Acknowledgements}

This investigation was generously supported by funds provided by the National Institute of General Medical Sciences (NIH R01 GM077309). The authors thank Dr. Justin Douglas and Sarah Neuenswander (KU) for assistance with NMR measurements and Dr. Todd Williams (KU) for HRMS analysis. The authors also thank the University of Kansas and the State of Kansas for support of our program. The authors also thank Materia, Inc. for supplying the metathesis catalyst.

\section{References}

1. Staunton, J.; Weissman, K. J. Nat. Prod. Rep. 2001, 18, 380-416. doi:10.1039/a909079g

2. Gupta, P.; Mahajan, N.; Taneja, S. C. Catal. Sci. Technol. 2013, 3, 2462-2480. doi:10.1039/c3cy00125c

3. Rychnovsky, S. D. Chem. Rev. 1995, 95, 2021-2040. doi:10.1021/cr00038a011

4. Friestad, G. K.; Sreenilayam, G. Org. Lett. 2010, 12, 5016-5019. doi:10.1021/ol1021417

5. Bode, E. S.; Wolberg, M.; Müller, M. Synthesis 2006, 557-588. doi:10.1055/s-2006-926315 See for a review polyol synthesis.

6. Mori, Y.; Suzuki, M. Tetrahedron Lett. 1989, 30, 4387-4388. doi:10.1016/S0040-4039(00)99367-5

7. Liu, D.; Kozmin, S. A. Org. Lett. 2002, 4, 3005-3007. doi:10.1021/ol026433j

8. Zacuto, M. J.; Leighton, J. L. Org. Lett. 2005, 7, 5525-5527. doi:10.1021/ol052373g

9. Aurrecoechea, J. M.; Suerro, R.; de Torres, E. J. Org. Chem. 2006, 71, 8767-8778. doi:10.1021/jo0614487

10. Trzoss, L.; Xu, J.; Lacoske, M. H.; Mobley, W. C.; Theodorakis, E. A. Chem. - Eur. J. 2013, 19, 6398-6408. doi:10.1002/chem.201300198

11. Krautwald, S.; Schafroth, M. A.; Sarlah, D.; Carreira, E. M. J. Am. Chem. Soc. 2014, 136, 3020-3023. doi:10.1021/ja5003247

12. Burke, M. D.; Schreiber, S. L. Angew. Chem., Int. Ed. 2004, 43, 46-58. doi:10.1002/anie.200300626 See for diversity oriented synthesis.

13. Louie, J.; Bielawski, C. W.; Grubbs, R. H. J. Am. Chem. Soc. 2001, 123, 11312-11313. doi:10.1021/ja016431e See for tandem, metathesis/hydrogenation.
14. Scholte, A. A.; An, M.-H.; Snapper, M. L. Org. Lett. 2006, 8, 4759-4762. doi:10.1021/ol061837n See for RCM/oxidation.

15. Seigal, B. A.; Fajardo, C.; Snapper, M. L. J. Am. Chem. Soc. 2005, 127, 16329-16332. doi:10.1021/ja055806j

See for RCM/Kharasch addition.

16. Ferrié, L.; Bouzbouz, S.; Cossy, J. Org. Lett. 2009, 11, 5446-5448. doi:10.1021/ol9021386

See for other tandem metathesis processes.

17. Wender, P. A.; Verma, V. A.; Paxton, T. J.; Pillow, T. H. Acc. Chem. Res. 2008, 41, 40-49. doi:10.1021/ar700155p

18. Trost, B. M. Science 1991, 254, 1471-1477. doi:10.1126/science. 1962206

19. Trost, B. M. Angew. Chem., Int. Ed. Engl. 1995, 34, 259-281. doi:10.1002/anie.199502591

20. Young, S. I.; Baran, P. S. Nat. Chem. 2009, 1, 193-205. doi:10.1038/nchem. 216 See for reviews on protecting group-free synthesis.

21. Hoffmann, R. W. Synthesis 2006, 3531-3541. doi:10.1055/s-2006-950311

22. Lipshutz, B. H.; Huang, S.; Leong, W. W. Y.; Zhong, G.; Isley, N. A. J. Am. Chem. Soc. 2012, 134, 19985-19988. doi:10.1021/ja309409e

23. Sheldon, R. A.; Arends, I. W. C. E.; Hanefeld, U. Green Chemistry and Catalysis; Wiley-VCH: Weinheim, 2007; pp 1-47. doi:10.1002/9783527611003.ch1

24. Ishikawa, H.; Suzuki, T.; Hayashi, Y. Angew. Chem., Int. Ed. 2009, 48, 1304-1307. doi:10.1002/anie.200804883

25. Ishikawa, H.; Honma, M.; Hayashi, Y. Angew. Chem., Int. Ed. 2011, 50, 2824-2827. doi:10.1002/anie.201006204

26. Hayashi, Y.; Umemiya, S. Angew. Chem., Int. Ed. 2013, 52, 3450-3452. doi:10.1002/anie.201209380

27. Whitehead, A.; McReynolds, M. D.; Moore, J. D.; Hanson, P. R. Org. Lett. 2005, 7, 3375-3378. doi:10.1021/ol0512886

28. Thomas, C. D.; McParland, J. P.; Hanson, P. R. Eur. J. Org. Chem. 2009, 5487-5500. doi:10.1002/ejoc.200900560

29. Venukadasula, P. K. M.; Chegondi, R.; Maitra, S.; Hanson, P. R. Org. Lett. 2010, 12, 1556-1559. doi:10.1021/ol1002913

30. Hanson, P. R.; Chegondi, R.; Nguyen, J.; Thomas, C. D.; Waetzig, J.; Whitehead, A. J. Org. Chem. 2011, 76, 4358-4370. doi:10.1021/jo2003506

31. Chegondi, R.; Tan, M. M. L.; Hanson, P. R. J. Org. Chem. 2011, 76, 3909-3916. doi:10.1021/jo200337v

32. Venukadasula, P. K. M.; Chegondi, R.; Suryn, G. M.; Hanson, P. R. Org. Lett. 2012, 14, 2634-2637. doi:10.1021/ol301007h

33. Chegondi, R.; Maitra, S.; Markley, J. L.; Hanson, P. R. Chem. - Eur. J. 2013, 19, 8088-8093. doi:10.1002/chem.201300913

34. Jayasinghe, S.; Venukadasula, P. K. M.; Hanson, P. R. Org. Lett. 2014, 16, 122-125. doi:10.1021/ol403110p

35. Kingsbury, J. S.; Harrity, J. P. A.; Bonitatebus, P. J., Jr.; Hoveyda, A. H. J. Am. Chem. Soc. 1999, 121, 791-799. doi:10.1021/ja983222u

36. Garber, S. B.; Kingsbury, J. S.; Gray, B. L.; Hoveyda, A. H. J. Am. Chem. Soc. 2000, 122, 8168-8179. doi:10.1021/ja001179g

37. Gessler, S.; Randl, S.; Blechert, S. Tetrahedron Lett. 2000, 41, 9973-9976. doi:10.1016/S0040-4039(00)01808-6

38. Myers, A. G.; Zheng, B.; Movassaghi, M. J. Org. Chem. 1997, 62, 7507. doi:10.1021/jo9710137

39. Haukaas, M. H.; O'Doherty, G. A. Org. Lett. 2002, 4, 1771-1774. doi:10.1021/ol025844x

40. Buszek, K. R.; Brown, N. J. Org. Chem. 2007, 72, 3125-3128. doi:10.1021/jo0622173 


\section{License and Terms}

This is an Open Access article under the terms of the Creative Commons Attribution License

(http://creativecommons.org/licenses/by/2.0), which permits unrestricted use, distribution, and reproduction in any medium, provided the original work is properly cited.

The license is subject to the Beilstein Journal of Organic Chemistry terms and conditions:

(http://www.beilstein-journals.org/bjoc)

The definitive version of this article is the electronic one which can be found at:

doi:10.3762/bjoc. 10.242 